\title{
Los cambios en la gestión del régimen de clases pasivas: ¿un ataque a las singularidades de los regímenes especiales de funcionarios?*
}

\section{Changes in the management of the Passive Classes regime: ¿an attack on the public employee of special staff regimes?}

\author{
Amparo Esteve-Segarra* \\ Profesora Titular \\ Universidad de Valencia. Magistrada Suplente Sala Social TSJ Comunidad Valenciana \\ ORCID ID: 0000-0003-3773-4668
}

Recibido: 5/03/2020

Aceptado: 3/04/2020

doi: https://doi.org/10.20318/labos.2020.5772

Resumen: $\quad$ El objetivo de este trabajo es analizar los cambios en la gestión del régimen de clases pasivas aprobados durante el 2020 dentro de la legislación de urgencia suscrita durante el estado de alarma. El traspaso de la gestión al Instituto Nacional de Seguridad Social plantea tres cuestiones: primero, si el traspaso es técnicamente adecuado; segundo, por qué se ha efectuado en un real decreto ley de medidas para paliar los efectos económicos del COVID-19 una medida que afecta a la gestión de las pensiones de funcionarios, y, tercero, qué puede suponer este cambio de gestión para las especialidades contenidas en este régimen especial.

Palabras clave: Funcionarios, protección social, pensiones, regímenes especiales, Seguridad Social.

Abstract: The objective of this paper is to analyze the changes in the management of the passive class regime approved during 2020 within the emergency legislation ratified during the state of alarm. The transfer of management to the National Social Security Institute raises three questions: firstly, whether the change is technically appropriate; secondly, why a measure that affects the management of civil servants' pensions has been approved in a royal decree-law of measures to mitigate the economic effects of COVID-19, and thirdly, that this change of management may entail for the specialties contained in this special regime.

Keywords: Civil sevants, social protection, pensions, special system, Welfare System.

* Trabajo realizado al amparo del Proyecto OTRI-UV, OTR2019-19507INVES, Clave 20190238.

**amparo.esteve@uv.es 


\section{El traspaso de la gestión en el régimen de clases pasivas al inss}

En el Real Decreto 15/2020, de 21 de abril, de medidas urgentes complementarias para apoyar la economía y el empleo, se contiene una disposición que, en teoría, no reviste ninguna conexión con los paquetes de medidas laborales y fiscales aprobados para paliar los efectos de la crisis económica derivada de la pandemia. Se trata del traspaso de competencia de la gestión de las pensiones de los funcionarios integrados en el Régimen de Clases Pasivas (en adelante, RCP) al Ministerio de Seguridad Social ${ }^{1}$.

Siete días después del RD-L 15/2020, se aprobó el Real Decreto de 28 de abril de 2020, que desarrolla la estructura orgánica básica del Ministerio de Inclusión, Seguridad Social y Migraciones. En dicha norma reglamentaria se fija que a partir del 6 de octubre de 2020 se iniciaría la entrada en vigor de los cambios para que la gestión del RCP se traspasara de competencias de manera transitoria a la Dirección General de Ordenación de la Seguridad Social y, después, al Instituto Nacional de Seguridad Social (en adelante, el INSS).

Las clases pasivas, esto es, el "colectivo de funcionarios que percibe haberes del Tesoro Público sin prestarle un servicio, hecho que se explica en consideración a los servicios que prestaron ellos o sus causahabientes" ${ }^{2}$ venían gestionando históricamente sus pensiones en el Ministerio de Hacienda. Y este cambio de competencias de gestión suscita tres interrogantes, a saber:

$1^{\circ}$ ¿Tiene sentido el traspaso de la gestión al INSS?

20. ¿Por qué se ha aprobado en un Real Decreto ley de medidas para paliar los efectos económicos del COVID-19, una disposición que afecta a la gestión de las pensiones de funcionarios?

$3^{\circ}$. ¿Qué supone este cambio de gestión para los pensionistas y para los funcionarios que están incluidos en Clases Pasivas, pero aún no son pensionistas?

\section{2. ¿Es un cambio técnicamente adecuado para la organización de nuestro sistema de protección social?}

El cambio de gestión del régimen de clases pasivas al INSS es lógico, aunque sólo constituye una pequeña transformación. La razón es que la existencia de un sistema de clases pasivas, es decir, de los regímenes especiales de pensiones para funcionarios no tiene sentido en un sistema de Seguridad Social integrado. Técnicamente uno de los principios de nuestro sistema de Seguridad Social es la unidad de gestión, y los regímenes especiales de funcionarios (en adelante, RESSFP) suponen una quiebra de este principio de unidad de gestión del sistema de Seguridad Social, puesto que los RESSFP no se gestionan por las entidades gestoras de la Seguridad Social, sino por entidades específicas.

La existencia de los RESSFP se explica esencialmente por una razón histórica. La Seguridad Social nació en España en 1900 con la Ley de Accidentes de Trabajo, que marca el inicio de la protección social de los trabajadores. Sin embargo, lo cierto es que, con anterioridad, para los servidores públicos se iniciaron algunas formas de protección social pobres e incompletas ${ }^{3}$, basadas en técnicas

\footnotetext{
${ }^{1}$ Cuya denominación, en la presente legislatura es técnicamente la de Ministerio de Inclusión, Seguridad Social y Migraciones, aunque en el presente trabajo se utilizará la de Ministerio de Seguridad Social.

2 JORDANA DE POZAS, L.: “Tendencias modernas sobre el Régimen de Clases Pasivas”, en Estudios Sociales y de Previsión, Tomo II, Volumen 2, Ministerio de Trabajo, INP, Madrid, 1961.

${ }^{3}$ En una primera etapa iban dirigidas a inválidos y veteranos de guerra retirados, así como a las familias de militares muertos en campaña. A partir de entonces, se crearon progresivamente pensiones de jubilación y retiro de funcionarios, así como las llamadas cesantías y determinadas pensiones de gracia para que distintos grupos o categorías de servidores públicos pudiesen alcanzar una pensión vitalicia cuando concluía el servicio activo. Ya en el siglo XIX proliferaron la creación de montepíos para distintos cuerpos de funcionarios, caracterizados
} 
mutualistas y de previsión social administrativa, y sujetas a vaivenes, que fueron muy anteriores a las de los trabajadores. Basta poner el ejemplo del retiro obrero para los trabajadores, que no se creó sino en 1919. Posteriormente, para los trabajadores se implantaron los seguros sociales, excluyéndose a los funcionarios que disponían ya de un sistema de protección específico. Concretamente, dicho sistema se articuló con carácter general para los diversos colectivos de funcionarios de la Administración central con el Estatuto de Clases Pasivas aprobado el 22 de octubre de 1926, en el que se optó por un sistema de protección social básica para cubrir los estados de necesidad provenientes de la vejez o invalidez (para los funcionarios que hubiesen abandonado el servicio activo), o para sus familiares (en caso de muerte y supervivencia), concebidas estas prestaciones como una especie de salario diferido. Por consiguiente, el RCP es un régimen peculiar, cuyos orígenes se remontan a los ańos veinte del siglo pasado con el Estatuto de Clases Pasivas de 1926. En concreto, el RCP ha sido un mecanismo de protección conjunto para los diversos tipos de funcionarios incluidos en alguno de los Regímenes Especiales de la función pública -y, por tanto, no integrados en el Régimen General de Seguridad Social (en adelante, RGSS) - que abandonasen el servicio activo. Concretamente, tiene por objeto garantizar al personal funcionario incluido en el mismo la protección frente a los riesgos de vejez, IP y muerte y supervivencia.

Ante la insuficiencia de la protección otorgada por el Estatuto de Clases Pasivas, se articuló una protección complementaria a través de diversas mutualidades de funcionarios, que habrían de resurgir de nuevo tras la Ley General de Mutualidades de 6 de diciembre de 1941.

La Ley de Bases de la Seguridad Social de 1963, preveía que, dadas las peculiaridades de dicho colectivo, se procedería a la creación de un Régimen Especial para los funcionarios públicos y militares, así como de otros regímenes especiales (para los funcionarios de Entidades Estatales Autónomas y para los funcionarios de organismos del Movimiento franquista). Sin embargo, dicha previsión fue doblemente incumplida.

En primer lugar, no se crearon esos regímenes especiales de funcionarios. De modo que los funcionarios no estatales fueron incluidos en el RGSS. En línea con la tendencia expansiva del $\mathrm{RG}$, se ha producido un progresivo proceso de ampliación del RGSS que integraría a un colectivo creciente de funcionarios, lo que ha supuesto paralelamente una disminución del ámbito subjetivo de los funcionarios encuadrados en los RESSFP en detrimento del RGSS. Así, se integran en el RGSS los funcionarios de las Comunidades Autónomas ${ }^{4}$, funcionarios de la Administración local 5 , funcionarios de la Administración institucional del Estado ${ }^{6}$, determinados funcionarios interinos y de empleo al servicio de la Administración Civil del Estado, el personal de carácter temporal

por la iniciativa pública en su creación y a los que obligatoriamente debían afiliarse los servidores públicos; notas éstas que diferenciaban a éstos de las cofradías y hermandades, nacidas de la iniciativa privada y donde la afiliación era voluntaria. Los Montepíos surgieron para cuerpos de funcionarios muy distintos, y se financiaban parcialmente por el Estado, y en parte, por las aportaciones de los propios funcionarios de sus sueldos. En 1831, en un contexto de fuerte crisis económica, el Estado se incautó de los fondos de los montepíos de funcionarios. Sobre los antecedentes históricos, vid. ALARCÓN CARACUEL, M.R. y GONZÁLEZ ORTEGA, S.: Las pensiones de los funcionarios públicos en España, Fundación Mapfre, Madrid, 1988.

${ }^{4}$ Tanto los de nuevo ingreso, como los funcionarios del Estado transferidos a las Comunidades Autónomas, que hayan ingresado o ingresen voluntariamente en Cuerpos o Escalas propios de la Comunidad Autónoma, cualquiera que sea el sistema de acceso (136.2 ap. $\mathrm{m}$ y n) TRLGSS). Existía una cierta controversia judicial si el paso a un cuerpo de funcionarios autonómicos por promoción interna o ascenso comporta un ingreso en el sentido de las normas mencionadas y el consiguiente cambio de un funcionario que tenía un Régimen Especial de Funcionarios al RGSS (vid. STS, Sala 3á, de 17-6-91, Rec. 8050/90). La cuestión sería resuelta normativamente al modificarse el TRSSFCE por la LPGE-2017, que impone la adscripción al RGSS de los funcionarios que por promoción se incorporen a la Administración autonómica o institucional, sin perjuicio de que mantengan su condición de mutualistas, que en ningún caso comportará la adscripción al RCP.

${ }^{5}$ Estos fueron integrados en virtud del RD 480/1983, de 2 de abril, que procedió a encuadrar en el RGSS al personal integrado en la MUMPAL, tanto de clases activas como pasivas, con efectos del 1 de abril de 1993. Esta integración supondría a la postre la desaparición de un régimen especial de seguridad social de los funcionarios de la Administración local, entonces existente.

${ }^{6}$ Aunque para éstos se preveía un régimen especial en la Ley de Bases de Seguridad Social, nunca llegó a constituirse, y quedaron integrados en el RGSS. 
de la Administración de Justicia, casi todos los funcionarios en prácticas ${ }^{7}$ y los altos cargos de las Administraciones públicas que no sean funcionarios públicos (art. 136.2.ñ) TRLGSS), el personal funcionario y no funcionario de organizaciones internaciones intergubernamentales o al servicio de la Administración de la Unión Europea, al que se permite celebrar un convenio especial ${ }^{8}$, el personal estatutario de los servicios de salud ${ }^{9}$ y el personal de administración y servicios de las universidades.

En segundo lugar, tampoco el régimen especial de funcionarios públicos, civiles y militares (art. 10.2.d) LGSS) se constituyó nunca como tal. En su lugar, se optó por mantener transitoriamente - pero aún perdura - el sistema prexistente de protección social de los funcionarios, con sus dos mecanismos de cobertura privativos de éstos, a saber: las del régimen de derechos pasivos y las mutualistas. De modo, que, aunque integrados formalmente los funcionarios dentro del sistema de Seguridad Social por la vía de los RESSFP, han mantenido una protección diferenciada, conservando sus formas peculiares e históricas de protección social.

En la actualidad, no existe un régimen de funcionarios, sino varios. La estructura de los llamados regímenes especiales de funcionarios se organizaría en cuatro piezas, reguladas cada una de ellas por leyes distintas: Mutualidad de Funcionarios Civiles del Estado (MUFACE) ${ }^{10}$, Mutualidad General Judicial (MUGEJU) ${ }^{11}$, Instituto Social de las Fuerzas Armadas (ISFAS) ${ }^{12}$ (recogiendo las tres mutualidades históricas) y el Régimen de Clases Pasivas. Cada una con sus leyes y correspondiente reglamento, y gestionado cada uno por una Mutualidad, MUFACE, para los funcionarios civiles, MUGEJU, como mutualidad general judicial y el ISFAS para los funcionarios militares y guardias civiles. Además, junto a esta estructura mutualista, y como ámbito común de protección para todos los funcionarios integrados en regímenes mutualistas, estaría el régimen de Clases Pasivas que reconoce pensiones vitalicias de jubilación o retiro (incluida la incapacidad permanente), muerte y supervivencia.

Esta compleja estructura bicéfala incide en la protección social de los funcionarios, que se caracteriza por quedar sometida a diferentes técnicas: a) de carácter mutualista y, b) de clases pasivas o de determinadas prestaciones del RGSS. De otro lado, dentro de la protección mutualista existe una notable fragmentación normativa, en algunos casos, difícilmente justificable, pues una buena parte de las Leyes Mutualistas de los funcionarios civiles, de justicia y militares, contienen preceptos muy semejantes o que son copias literales unos de otros, actuando el régimen de funcionarios civiles como una suerte de régimen general de los otros dos regímenes especiales de funcionarios.

Además, existe una fragmentación de gestión, cada Mutualidad depende de un ministerio, MUFACE del Ministerio de Administraciones públicas; MUGEJU, del Ministerio de Justicia e ISFAS del Ministerio de Defensa. A estas tres mutualidades se sumaba el RCP para determinados funcionarios que abandonasen el servicio activo, afiliados antes del 1-1-2011. Ello quiebra el principio de unidad de gestión de la Seguridad Social, puesto que las Mutualidades no se gestionan por las

\footnotetext{
${ }^{7}$ En concreto, los que aspiren a incorporarse a cuerpos y escalas de funcionarios no sujetos al RCP.

${ }^{8}$ Regulado según el tipo de organización bien en el RD 2072/1999, de 30 de diciembre, bien en el RD 1658/1998, de 24 de julio.

${ }^{9}$ Dicho personal, que tiene la condición de funcionario con una relación funcionarial especial, está incluido en el campo de aplicación del RGSS (arts. 1 y 17.1.i) Ley 55/2003, de 16 de diciembre, por el que se aprueba el Estatuto Marco de este personal).

${ }^{10}$ Codificado por RDLeg. 4/2000, de 23 de junio, que aprueba el Texto Refundido de la Ley sobre Seguridad Social de los Funcionarios Civiles del Estado (TRSSFCE). Se desarrolla por el Reglamento General del Mutualismo Administrativo (RD 375/2003, de 28 de marzo, en adelante RGMA).

${ }^{11}$ Regulado por el RDLeg. 3/2000, de 23 de junio, por el que se aprueba el Texto Refundido sobre disposiciones legales vigentes sobre el Régimen Especial de la Seguridad Social del personal al servicio de la Administración de Justicia (TRLSSAJ) y como norma reglamentaria de desarrollo, el Reglamento del Mutualismo Judicial, aprobado por el RD 1026/2011, de 15 de julio (RMJ).

${ }^{12}$ Regulado por el RDLeg. 1/2000, de 9 de junio, por el que se aprueba el Texto Refundido de la LGSS de las Fuerzas Armadas (TRLSSFA). Su desarrollo se produce por el RD 1726/2007, de 21 de diciembre por el que se aprueba el Reglamento General de la Seguridad Social de las Fuerzas Armadas (RGSSFA).
} 
entidades gestoras de la Seguridad Social, sino por entidades específicas. Y hasta el 2020, también el RCP tenía una gestión separada de las entidades de Seguridad social.

La dispersión se acentuaría aún más porque los RESSFP no integran a todos los funcionarios (ahora ya más de la mitad de éstos se integra no en las mutualidades de funcionarios, sino en el RGSS). Sin embargo, el hecho de que los funcionarios queden encuadrados en dos regímenes de protección muy distintos (RGSS y RESSFP) sin que exista un criterio lógico de distinción, más allá del mantenimiento de una situación histórica, no parece que se adecúe a un sistema racional de Seguridad Social. Por consiguiente, si el cambio de gestión de una de las cuatro patas de los Regímenes Especiales de Funcionarios contribuye a la integración en la gestión de los sistemas de protección social, cabría preguntarse por qué no se ha abordado antes, y se ha mantenido una estructura tan caótica.

Existirían varias razones. En primer lugar, una cierta inercia histórica y desidia normativa; en segundo lugar, la resistencia de los propios colectivos de funcionarios integrados en los regímenes especiales que no estaría dispuestos a renunciar a sus regímenes tradicionales de protección social; y, en tercer lugar, los gobiernos anteriores habrían apostado por una integración lenta de la protección social de los funcionarios de modo que el RCP morirá de forma natural, cuando ya no exista ningún sujeto protegido. El Régimen de Clases Pasivas siempre ha sido una patata caliente que ningún gobierno anterior de uno u otro signo político ha querido tocar demasiado. De hecho, la forma de acabar con él ha sido la de dejarlo fenecer por extinción natural imponiendo la integración obligatoria en el RGSS a efectos de la protección otorgada en el sistema de Clases Pasivas, de los funcionarios que accedieran a dicha condición a partir de 1 de enero del 2011. El RCP está destinado a extinguirse, manteniéndose transitoriamente únicamente para los colectivos adscritos al mismo con anterioridad a dicha fecha ${ }^{13}$. De esta suerte, sólo está vigente para regular derechos ya causados, o los que en el futuro se puedan causar por las personas incluidas en el mismo antes del 1 de enero del $2011^{14}$. El RCP ya no admite nuevas afiliaciones y los nuevos funcionarios tienen la cobertura de las prestaciones de jubilación o retiro, muerte y supervivencia por el RGSS. El hecho de que el régimen fuera a desaparecer abonaba la postura de anteriores gobiernos de mantener la tradicional gestión separada de los funcionarios integrados en las Clases Pasivas respecto a los regímenes de seguridad social.

\section{3. ¿Por qué se ha aprobado en un real decreto ley de medidas para paliar los efectos económi- cos del Covid-19 una medida que afecta a la gestión de las pensiones de funcionarios?}

En la exposición de motivos del Real Decreto-ley 15/2020 se justifica en que, en una norma anterior, en concreto en una norma reglamentaria aprobada para la restructuración de diversos departamentos ministeriales, y en concreto la organización del Ministerio de Seguridad Social, ya se preveía

\footnotetext{
${ }^{13}$ Art. 20 y DT 4a RDL 13/2010, de 3 de diciembre.

${ }^{14}$ Así, están incluidos en el RCP los funcionarios incluidos antes del 2011 de los siguientes cuerpos: los funcionarios de carrera de carácter civil de la Administración del Estado, el personal militar de carrera y el de las escalas de complemento y reserva naval y el de tropa y marinería profesional que tuvieran adquirido el derecho a permanecer en las Fuerzas Armadas hasta la edad de retiro, los funcionarios de carrera de la Administración de Justicia, los funcionarios de Carrera de las Cortes Generales, los funcionarios de carrera de otros órganos constitucionales, los expresidentes, vicepresidentes, ministros, secretarios de estado y asimilados y otros altos cargos constitucionales, los alumnos de las academias y escuelas militares, el personal militar de empleo y el de las escuelas de complemento y reserva naval y el de la tropa y marinería profesional que no tenga adquirido el derecho a permanecer en las fuerzas armadas hasta la edad de retiro.

Por otra parte, también están incluidos otros colectivos que no tienen el "status" propio de los funcionarios públicos, como, altos cargos de la Administración (los expresidentes, vicepresidentes y ministros del gobierno de la nación), así como otros altos cargos de las Instituciones del Estado (expresidentes del Congreso de los diputados y del Senado, del Tribunal de Cuentas y del Consejo de Estado, del Tribunal Supremo, Tribunal Constitucional, del Consejo General del Poder Judicial y ex Defensores del Pueblo y Fiscales Generales del Estado), en favor de los cuales se reconocen determinadas prestaciones cuando fallecen o cuando alcanzan la edad de jubilación de los funcionarios. Excepcionalmente para estos últimos se mantiene vigente el RCP (art. 20.2 del RDL 13/2010, ap. i del art. 2.1 y art. 51 del TRLCPE).
} 
el cambio de gestión en el RCP. Ciertamente, el art. 22 del Real Decreto 2/2020, de 12 de enero, por el que se reestructuraron en dicho año los departamentos ministeriales establecía que: "Corresponde al Ministerio de Inclusión, Seguridad Social y Migraciones la propuesta y ejecución de la política del Gobierno en materia de Seguridad Social y clases pasivas...”. Esta expresa alusión a las clases pasivas como competencia del Ministerio de Seguridad Social, no se contenía en otros reales decretos anteriores de reorganización de los departamentos ministeriales, que se suelen aprobar al principio de cada legislatura. En todo caso, parece claro que el gobierno pretendía llevar la gestión de Clases Pasivas al Ministerio encargado de la gestión de Seguridad Social ya antes de la declaración del estado de alarma. En la exposición de motivos del Real Decreto-ley 15/2020 se justifica la urgencia y necesidad del cambio de gestión del RCP señalando esencialmente que como la tramitación parlamentaria de dichos cambios normativos para operar el traspaso en la vía ordinaria retrasaría la organización del Ministerio de Seguridad Social, se generaría incertidumbre en la gestión de la delicada cuestión de las pensiones ${ }^{15}$.

La justificación gubernamental del cambio de gestión abre a su vez varios interrogantes, a saber: ¿es una justificación suficiente para realizar un cambio en el ámbito de una norma de urgencia como un Real Decreto-ley? ¿existiría una extraordinaria y urgente necesidad de efectuar el traspaso de gestión? ¿podría anularse por este motivo el cambio de gestión en el régimen? A primera vista, no parece que existiera una situación perentoria que implicase la necesidad de meter en una norma dedicada a medidas económicas y de empleo por la crisis del COVID-19, un cambio en la gestión de la gestión de pensiones de Clases Pasivas, que no guardan ninguna relación con otras medidas vinculadas a la crisis sanitaria. Pero ello no implica necesariamente que la vía empleada sea ilegal.

Como se deduce claramente de la redacción del art. 86.1 CE, el Decreto-ley se concibe como un mecanismo legislativo de carácter claramente excepcional. Justamente, en este último sentido, la "habitualidad" en el uso del Decreto-ley para aprobar reformas laborales y de Seguridad Social, plantea la cuestión de si está justificada su utilización en el caso del traspaso de la gestión del RCP, tanto por la materia que es objeto de Decreto-ley, como por el requisito de la urgencia y extraordinaria necesidad en su aprobación.

De conformidad con el art. 86.3 de la CE, la regulación por Decreto-ley se reserva a los casos de "extraordinaria y urgente necesidad", excluyéndose para determinadas materias, pues "no podrá afectar al ordenamiento de las instituciones básicas del Estado, a los derechos, deberes y libertades de los ciudadanos regulados en el título I, al régimen de las Comunidades Autónomas ni al derecho electoral general'. Además, ha de remitirse al Congreso de los Diputados, que habrá de pronunciarse en el plazo de 30 días siguientes al de su promulgación, con vistas a su convalidación o derogación (art. 86.3 CE). Durante dicho plazo, las Cortes pueden tramitar el Decreto-Ley también como proyecto de ley por el procedimiento de urgencia, que es lo que ha acaecido en este caso ${ }^{16}$. La literatura sobre el abuso del Real Decreto ley y la crisis del principio de legalidad es abundantísima, y constituye por sí misma, una demostración clara de la importancia de estos fenómenos, a los que se viene pres-

\footnotetext{
${ }^{15}$ Se aduce: "En esta linea, el calendario para llevar a cabo las modificaciones legales necesarias para la integración efectiva del Régimen de Clases Pasivas en el Ministerio de Inclusión, Seguridad Social y Migraciones se ha visto radicalmente alterado por la crisis sanitaria provocada por el COVID-19 en la que se han centrado los esfuerzos de la acción del Gobierno en las últimas cinco semanas. En este sentido, es razonable considerar que esos cambios normativos no pueden ser aprobados mediante el procedimiento ordinario de tramitación parlamentaria, pues ello implicaria que, hasta la aprobación de tales reformas legislativas, la estructura organizativa derivada del Real Decreto 2/2020 no podría materializarse y, por lo tanto, los órganos competentes no podrian desarrollar las funciones que tienen atribuidas con arreglo al citado Real Decreto; circunstancia que generaria inseguridad juridica e incertidumbre en una materia, las pensiones, particularmente sensible para el conjunto de la ciudadania. Tal motivo justifica la extraordinaria y urgente necesidad de la situación y la conexión con ella de las medidas adoptadas." .

${ }^{16}$ Convalidado por resolución de 13 de mayo de 2020, del Congreso de los diputados, por la que se ordena la publicación del acuerdo de convalidación del Real decreto-ley 15/2020, de 21 de abril, de medidas urgentes complementarias para apoyar la economía y el empleo.
} 
tando una atención creciente ${ }^{17}$. Y es que el imperio de la ley aparece claramente, como instrumento de ordenación emanado del Parlamento, como representante del pueblo del que emanaba el poder soberano ${ }^{18}$. El desgaste del principio de legalidad cuando se utiliza inadecuadamente el real decreto ley guarda una estrecha conexión con la relativización de la teoría de la división de poderes. En efecto, la comprobación del contexto actual de poderes normativos ha permitido constatar que la división tradicional en potestad legislativa, ejecutiva y judicial, ya no coincide exactamente con la distribución de funciones en ejecutivas y legislativas. En este sentido, el tema conecta directamente con la pérdida de protagonismo del Parlamento y tiene una manifestación clara, desde el plano que aquí interesa, en el fenómeno de administrativización normativa, donde existe una importante asunción por parte del ejecutivo de relevantes parcelas de regulación.

Como se deduce claramente de la redacción del art. 86.1 CE, el Decreto-ley se concibe como un mecanismo legislativo de carácter claramente excepcional. Justamente, en este último sentido, el uso del Decreto-ley para aprobar una reforma como la operada en la gestión del RCP, plantea la cuestión de si está justificada su utilización tanto por la materia que es objeto de Decreto-ley, como por el requisito de la urgencia y extraordinaria necesidad en su aprobación. El Real Decreto Ley se ha apoyado en una motivación típica de este tipo de norma. En el caso analizado se alude a que esta forma de ley permite su inmediata ejecutividad y el retraso que supondría esperar a la tramitación parlamentaria normal. Argumento este último que como apuntará PALOQUEME sobre una norma anterior (el RDL 5/2001, de 2 de marzo), cuando se emplea no puede calificarse sino de claramente redundante ${ }^{19}$. Así, se hace hincapié en que el Decreto-ley, por su mayor rapidez, evitaría distorsiones al producirse la reestructuración del ministerio de Seguridad social con mayor rapidez. Si se lleva a sus últimos términos, esta misma argumentación serviría para toda reforma en materia de pensiones, que siempre podría crear distorsiones, al ser siempre un tema sensible.

En todo caso, la jurisprudencia del Tribunal Constitucional es bastante tolerante, lo que puede ayudar a comprender mejor lo que ha permitido la aceptación y convalidación de este uso abusivo del recurso al Decreto-Ley. En efecto, la posición del Tribunal Constitucional en esta materia se caracteriza por su laxitud, al interpretar que la posibilidad de dictar Decretos-leyes no se circunscribe a situaciones de absoluta excepcionalidad, "sino para objetivos normales de gobernabilidad que no puedan ser satisfechos sin la utilización de ese instrumento, a causa de la urgencia de la situación que se trata de regular" ${ }^{20}$. En este sentido, el Tribunal Constitucional ha interpretado el requisito del carácter extraordinario, como la dificultad de prever situaciones concretas, y el requisito de urgencia como la exigencia de una regulación más inmediata "en un plazo más breve que el requerido por la vía normal o por el procedimiento de urgencia para la tramitación parlamentaria de las leyes" (STC 1983/6, de 4 de febrero, BOE de 9 de marzo FJ. 5º, y en el famoso caso Rumasa, STC 111/1983, de 2 de diciembre, $\mathrm{BOE}$ de 14 de diciembre, FJ. $\left.6^{\circ}\right)^{21}$. En cuanto a los requisitos de orden material, se ha entendido que

${ }^{17}$ Vid., en este sentido, por ejemplo, MUÑOZ MACHADO, S.: "Las deformaciones del ordenamiento jurídico y la aplicación de las leyes en el nuevo sistema constitucional”, en su obra Cinco estudios sobre el poder y la técnica de legislar, Civitas, Madrid, 1986, pp. 181 y ss. HIERRO, L. L.: "El imperio de la ley y la crisis de la ley”, Doxa, 1996, núm. 19, pp. 287-308. CIRIANO VELA, C. D.: Principio de legalidad e intervención económica, Atelier, Barcelona, 2000.

${ }^{18}$ Sobre esta cuestión, vid., por ejemplo, SANTAMARÍA PASTOR, J.A.: "Principio de legalidad (Derecho Constitucional)", en la Enciclopedia Jurídica Básica, Vol. III, 1a ed., Civitas, Madrid, 1995, pp. 5078 y ss.

${ }^{19}$ PALOMEQUE LÓPEZ, M.C.: "La versión 2001 de la reforma laboral permanente", Revista de Derecho Social, núm. 15, 2001, p. 13. La abusiva utilización del Decreto-ley también fue un lugar común entre los comentaristas de la reforma, que no encontraron en ningún caso, las pretendidas razones de urgencia. En este sentido, puede verse ALARCÓN CARACUEL, M.C.: "Reflexión crítica sobre la reforma laboral de 2001", Revista de Derecho Social, núm. 15, 2001, p. 40.

${ }^{20}$ LÓPEZ GARRIDO, D.: "Reflexiones sobre la constitucionalidad del Real Decreto Ley 1/1992, de medidas urgentes sobre fomento del empleo y protección por desempleo", REDC, núm. 38, 1993, p. 30.

${ }^{21} \mathrm{Y}$, con anterioridad, STC 29/1982, de 31 de mayo, un comentario de este pronunciamiento puede verse en SEMPERE NAVARRO, A.V.: "El lugar del Decreto-Ley en el cuadro de fuentes jurídico-laborales (Sentencia 29/1982, de 31 de mayo, pronunciada por el Pleno del Tribunal Constitucional en el recurso de inconstitucionalidad 238/1981”, RPS, núm. 135, pp. 239 y ss. 
no toda regulación que afecte a las instituciones básicas del Estado, a los derechos, deberes y libertades de los ciudadanos regulados en el título I, y al resto de materias referidas en el art. 86.3 CE, está excluida para el Decreto-ley ${ }^{22}$, sino sólo la que afecta a "los elementos estructurales, esenciales o generales de la organización y funcionamiento de las instituciones estables básicas, pero no, en cambio, a cualesquiera otros aspectos accidentales o singulares de las mismas" (STC 60/1986, de 20 de mayo, FJ. 4º).

Así que, atendiendo a la línea marcada por la jurisprudencia constitucional, el problema es que, en la práctica, se han relativizado estos requisitos materiales que habilitan el juego del Decretoley. Fenómeno que, a mi entender, se ha visto fuertemente favorecido por una interpretación constitucional reacia a entrar a valorar las medidas y las razones aducidas por el Gobierno ${ }^{23}$. Aunque esta autolimitación pudiera ser hasta cierto punto razonable, a la postre, ha conducido a una utilización abusiva por parte del Ejecutivo. En definitiva, se ha hecho un uso contrario de la directriz inicial marcada por el Tribunal Constitucional de que el requisito de extraordinaria y urgente necesidad, no constituya una expresión "vacía de significado".

En este sentido, aunque se ha insistido en que el Decreto-ley no puede dictarse por razones de "oportunidad política", sino por causas de "necesidad"24, lo cierto es que aprovechando la flexible y laxa doctrina establecida por el Tribunal Constitucional2 ${ }^{25}$, el Gobierno parece haberse acostumbrado a la posibilidad de recurrir a esta legislación excepcional frente al sistema de normación general. De esta suerte, paradójicamente, la vía legislativa pasa a convertirse en la práctica en el "poder normativo de excepción".

No debe desconocerse la importancia de esta cuestión, que afecta al mismo pilar del Estado de Derecho con la división de poderes. Concretamente, constituye una manifestación más del protagonismo del Ejecutivo, acentuada por la situación del estado de alarma.

Entonces si no existía una extraordinaria y urgente necesidad, ¿por qué razón el gobierno ha decidido acometer este cambio mediante una legislación de urgencia? Creo que sinceramente responde a que el estado de alarma ha ofrecido la oportunidad de iniciar un cambio en la siempre delicada cuestión de las pensiones de funcionarios públicos aprovechando la multitud de legislación de urgencia aprobada durante la pandemia. La aprobación de reformas laborales y de Seguridad Social mediante esta forma legislativa se había convertido, en algo más que en una vía excepcional, ya antes de la crisis sanitaria, económica y social, acentuándose con ésta.

$Y$ es que conviene apuntar otra razón estratégica que abonaría la conveniencia gubernamental de abordar el cambio de gestión del RCP durante este estado de alarma. Este estado dificulta enormemente a las organizaciones sindicales de funcionarios plantear huelga frente un traspaso de gestión. Téngase en cuenta que la huelga durante el estado de alarma, pese a no producirse formalmente una suspensión del derecho durante el estado de alarma ${ }^{26}$, plantea serios inconvenientes para su articulación, y además, y lo que es más importante, sería percibida seguramente de manera muy negativa por la opinión pública en una situación de crisis económica y altos niveles de desempleo.

\footnotetext{
${ }^{22}$ Así, se ha entendido que si no se reduciría el papel del RD-L 2 "a la nada" pues "es difícil imaginar alguno cuyo contenido no afectase a algún derecho comprendido en el Título $I$ ", lo que cabe interpretar de esta exclusión es que no se admite que "por decreto-ley se regule el régimen general de los derechos y libertades del Título $I$....(o) se vaya en contra del contenido o de elementos esenciales de alguno de tales derechos" (STC 111/1983, de 2 de diciembre, citada, FJ. $8^{\circ}$ ).

${ }^{23}$ Como señalara la STC 182/1997, de 28 de octubre, BOE de 28 de noviembre, "el control que compete al Tribunal Constitucional en este punto es un control externo, en el sentido de que debe verificar, pero no sustituir el juicio politico o de oportunidad que corresponde al Gobierno y al Congreso de los Diputados en el ejercicio de la función de control parlamentario" (FJ. 40).

${ }^{24}$ LÓPEZ GARRIDO, D.: "Reflexiones sobre la constitucionalidad ... ", op. cit., p. 40.

${ }^{25}$ SSTC 6/1983, de 4 de febrero, FJ. 5º 60/1986, de 20 de mayo, FJ. 3º, 29/1986, de 20 de febrero, BOE de 21 de marzo, FJ. $2^{\circ}$, y $182 / 1997$, de 28 de octubre, FJ. $3^{\circ}$.

${ }^{26}$ Sobre esta cuestión, me remito a las consideraciones efectuadas en un anterior trabajo. Vid. ITUREN OLIVER, A. y ESTEVE SEGARRA, A., "El derecho de huelga en tiempos del estado de alarma por el COVID-19". Trabajo y Derecho, núm. 65, 2020, pp. $1-21$.
} 


\section{4. ¿Qué supone este cambio de gestión para los pensionistas y para los funcionarios incluidos en clases pasivas?}

El cambio en la gestión del Ministerio de Hacienda hacia la Dirección General de Ordenación de Seguridad Social, no ha afectado directamente a los pensionistas. Es cierto que se han producido una reforma en la normativa que regula las clases pasivas, pero los cambios de articulado, aunque numerosos, son en síntesis, reformas técnicas dirigidas a aclarar el órgano gestor de las prestacio$n^{27}{ }^{27}$. Pese a la alarma creada en algunos medios de comunicación entre los pensionistas, no se han modificado pues ninguna de las prestaciones del RCP, ni se han alterado sus requisitos, ni cuantías. Tampoco respecto a los futuros pensionistas se han producido cambios en las modalidades o coberturas de las pensiones del sistema. Ni tampoco en las distintas mutualidades de funcionarios, que tienen una gestión y una regulación separada del RCP.

Se trata pues de un cambio de gestión, que en ningún modo supone la integración del RCP en el RGSS. De manera que se mantiene como régimen a extinguir, traspasándose únicamente su gestión al INSS. Si ello es así, ¿por qué algunos sindicatos en la función pública han mostrado preocupación por estos cambios meramente técnicos ${ }^{28}$ ? Pues sencillamente porque el hecho de que, siendo el mismo organismo gestor, transitoriamente la Dirección General de Ordenación de Seguridad Social, y posteriormente el INSS, es probable que el cambio abra una vía para cuestionar la autonomía y separación de los RESSFP, debatiéndose si determinadas conquistas o, si se quiere utilizar una connotación negativa, prerrogativas sean más evidentes y, con ello más difíciles de justificar ${ }^{29}$.

\section{Singularidades de los regímenes especiales de funcionarios respecto al Régimen General de Seguridad Social}

La existencia de especialidades dentro de los regímenes especiales de funcionarios ha sido criticada por algunos de los mejores estudiosos de nuestro sistema de Seguridad Social ${ }^{30}$. Así, se ha aludido a que dentro de los regímenes de Seguridad Social de los funcionarios se encuentra "la mayor desigualdad, la insolidaridad máxima" y que son un síntoma de "descomposición de un sistema pretendidamente unificado" con "privilegios ancestrales o castas en el sector público carentes de justificación en la actualidad”. Desde luego, la opinión es negativa y vendría a refrendar una mirada a la protección social ofrecida por estos regímenes como una situación de prerrogativas para determinados funcionarios (los integrados en el RCP), respecto a otros funcionarios y trabajadores integrados en el RGSS.

${ }^{27}$ El Real Decreto Ley 15/2015, de 21 de abril modificaría en la disposición final primera los arts. 8.2, 11, 12, 13, 14.2, 16.1, art. 34, 37 quarter, 47 y disposiciones adicionales $2^{\mathrm{a}}$, 15a y 18 del Real Decreto Legislativo 670/1987, de 30 de abril, por el que se aprueba el Texto Refundido de Clases Pasivas. Además, introduciría otros cambios técnicos en la DA 5 a $7^{\mathrm{a}}$ y en la DT 2a del Real Decreto Ley. En síntesis, estos cambios se limitarían a sustituir las referencias a la Dirección General de Costes de Personal y Pensiones Públicas del Ministerio de Economía y Hacienda o a la Dirección General de Personal del Ministerio de Defensa, sustituyéndolas por las nuevas entidades que se ocuparán de la gestión, es decir, el Instituto Nacional de la Seguridad Social en materia que hará dicha gestión de las mismas prestaciones vigentes (transitoriamente a la Dirección General de Ordenación de la SS).

${ }^{28} \mathrm{Vid}$. por ejemplo, reseñas en diferentes webs de sindicatos. https://ste-clm.com/cambios-en-la-gestion-de-las-pensiones-del-regimen-de-clases-pasivas/, O en la prensa: https://cincodias.elpais.com/cincodias/2020/04/23/economia/1587654087_716021.html

${ }^{29}$ Sobre la confrontación entre el RGSS y los RESSFP, vid. RODRÍGUEZ RAMOS, M.J.: "Los derechos de Seguridad Social de los funcionarios públicos: convergencias y divergencias con el Régimen General”. Recuperable: https://idus.us.es/bitstream/handle/11441/44007/Los\%20derechos\%20de\%20seguridad\%20social

${ }^{30}$ Vid. VIDA SORIA, J.: "Sobre la inactualidad del Régimen de Clases pasivas", Documentación Administrativa, núm. $71,1963$. También, ALARCÓN CARACUEL, M.R. y GONZÁLEZ ORTEGA, S.: Las pensiones de los funcionarios públicos en España, Fundación Mapfre, Madrid, 1988. 
Es verdad que en el ámbito de los regímenes especiales de funcionarios se han producido un acercamiento con el RGSS en algunos aspectos, en particular con tratamiento de las pensiones públicas en cuanto a los topes, las revalorizaciones y las cuantías máximas y mínimas. Sin embargo, se mantienen otras especialidades que interesa abrir al debate.

\subsection{La asistencia sanitaria privada para funcionarios públicos}

Los Regímenes Especiales de funcionarios ofrecen peculiaridades importantes en cuanto a la forma particular de provisión de la asistencia sanitaria con posibilidad de acudir a los servicios públicos de salud o a entidades de seguro privadas. Este es uno de los aspectos más llamativos y singulares de la protección social de los funcionarios públicos que están integrados en los RESSFP, que pese a ser funcionarios públicos pueden recibir la asistencia sanitaria a través de entidades de seguro privadas. Ello introduce una diferencia con cualquier otro régimen de Seguridad Social donde procede la adscripción obligatoria de los afiliados a los servicios públicos de salud. De este modo, corresponde al mutualista beneficiario optar en el mes de enero por recibir la asistencia sanitaria por el sistema de sanidad pública o privada, y de preferirse por el sistema privado (opción en la práctica claramente mayoritaria ${ }^{31}$ ), elegir la entidad de seguro privada entre las varias con las que cada mutualidad tiene suscrito el correspondiente concierto ${ }^{32}$. En el ámbito castrense, además, está la posibilidad complementaria de acudir a la Sanidad militar ${ }^{33}$.

Hay que tener en cuenta que ello es muy importante, pues del catálogo de la acción protectora de las mutualidades de funcionarios, la prestación más importante es la de asistencia sanitaria y determinadas prestaciones en especie.

\subsection{Un régimen de prestaciones sanitarias complementarias y de asistencia social más beneficioso.}

En los Regímenes Especiales de Funcionarios se mantienen prestaciones sociales y de asistencia social por encima de otros regímenes. Además de la particularidad antes reseñada de la forma de recibir la asistencia sanitaria, existen otras, por ejemplo, en el pago de los medicamentos. Por ejemplo, se mantiene alguna diferencia sustancial en el pago de los medicamentos (inclusive para los funcionarios públicos ya jubilados), que es de un 30 por 100 del precio frente al $10 \%$ de aportación farmacéutica de los jubilados de pensiones contributivas ${ }^{34}$. Sin embargo, en contrapartida las mutualidades de funcionarios prevén algunas ayudas adicionales de carácter sociosanitario sin parangón en otros Regímenes (ayudas económicas para prestaciones dentarias, oftalmológicas, prestaciones ortoprotésicas, para gastos por desplazamiento para recibir asistencia sanitaria, para gastos de internamiento de enfermos psiquiátricos, etc.) y, además, como peculiaridad los titulares y los beneficiarios son depositarios de los talonarios de recetas. Muchas prestaciones de asistencia social, al no reconocerse como un derecho subjetivo, están sujetas a disponibilidad presupuestaria y han sufrido recortes.

\footnotetext{
${ }^{31}$ Vid. Memorias Anuales de MUFACE, MUGEJU e ISFAS, en las correspondientes webs de estas entidades donde se hacen constar los datos anuales de la modalidad de cobertura elegida.

${ }^{32}$ Sobre este sistema de conciertos, vid. HERNÁNDEZ BEJARANO, M.: La protección sanitaria en los regímenes especiales de Seguridad Social de los funcionarios públicos, Bomarzo, 2017, Albacete.

${ }^{33}$ Regulada por la Orden 17/12, de 15 de marzo.

${ }^{34}$ Vid. art. 94.9. bis de la Ley 29/2006, del Medicamento. Este mismo porcentaje se fija como aportación del usuario en cuanto a la prestación ortoprotésica, salvo para determinados productos de aportación reducida, donde el porcentaje a sufragar por el usuario será del 10\% (art. 9.5 RD 1506/2012) o la gratuidad en casos de hospitalización o tratamientos derivados de contingencias profesionales. En lo demás, la prestación farmacéutica es similar a la del RGSS, incluyendo y excluyendo similares documentos y productos.
} 
La asistencia sanitaria se dispensará a los mutualistas, a los jubilados mutualistas, así como a los beneficiarios a su cargo. En este sentido, otra singularidad es que a los RESSFP no les resulta aplicable la normativa que regula en sentido restrictivo la condición de asegurado y beneficiario en punto a la asistencia sanitaria en España con cargo a fondos públicos, y mantienen el régimen específico de cada Mutualidad ${ }^{35}$.

\subsection{Un sistema más ventajoso de prestaciones por muerte y supervivencia}

Existen otras diferencias en el RCP, por lo que se refiere a las prestaciones por muerte y supervivencia, que son más favorables en tres aspectos.

En primer lugar, no se exige período de carencia, lo cual resulta en una obvia ventaja respecto al RGSS. A diferencia del RGSS, donde se exigen 500 días dentro de los cinco años anteriores, si el fallecimiento deriva de enfermedad común (salvo para las pensiones de orfandad, si al fallecer el causante, éste se encuentra en situación de alta asimilada).

En segundo lugar, la cuantía es más beneficiosa, en general, porque las pensiones de viudedad, orfandad y a favor de padres se obtienen aplicando los porcentajes al haber regulador teórico que hubiera correspondido al causante al cumplir la edad de jubilación similar. Es decir, se toma para calcular la base reguladora, lo que habría correspondido al causante, como si hubiera prestado servicios efectivos todos los años que faltaran al interesado para cumplir la edad de jubilación forzo$\mathrm{sa}^{36}$. Además, en la pensión de viudedad, la cuantía en el RCP se obtiene aplicando a un porcentaje del 50 por cien sobre la pensión ordinaria o haber regulador teórico que hubiera correspondido al causante al cumplir la edad de jubilación forzosa ${ }^{37}$.

En tercer lugar, existen las pensiones extraordinarias de jubilación y de muerte y supervivencia, cuando el retiro o la muerte se produce por un accidente o enfermedad en acto de servicio o se causan como consecuencia del mismo ${ }^{38}$. Se les otorga un tratamiento privilegiado a estas pensiones que se manifiesta concediendo una cuantía superior (el doble) a la que se concede en pensiones de jubilación o de muerte y supervivencia derivada de enfermedad o accidente común. Para la determinación de la cuantía, se debe calcular la pensión de jubilación que teóricamente correspondería al fallecido, con la ficción de computar los años efectivos de servicios más los años completos que le faltaran para alcanzar la correspondiente edad de jubilación o retiro forzoso (que se consideran como si se hubieran prestado efectivamente en su puesto). La base reguladora es del 200 por 100 de esta cantidad (art.

${ }^{35}$ DA 7a del RD 1192/2012. Para el régimen de cada mutualidad: en MUFACE, art. 15TRSSFCE y arts. 67 a 69 RGMA; en MUGEJU, art. 15 TRLSSAJ, y arts. 63 y 64 RMJ; y en ISFAS, art. 12.1 TRLSSFA.

${ }^{36}$ La base reguladora de las pensiones se calcula de forma parcialmente distinta si ya era pensionista de jubilación en el momento del fallecimiento, pues la base reguladora es la pensión ordinaria de jubilación o retiro que efectivamente se hubiera señalado al causante, debidamente actualizada en su caso. Si el pensionista de jubilación o retiro por IP para el servicio no tuviera acreditados como mínimo 20 ańos de servicios efectivos al Estado, la base reguladora será la pensión de jubilación o retiro en la cuantía inicialmente reconocida del 75 por ciento. Por otra parte, si el causante fallece en situación de excedencia voluntaria, de suspensión firme, separado del servicio o en situación militar legalmente asimilable, es la pensión de jubilación que le hubiera correspondido al causante, pero considerando solamente por los servicios prestados hasta el momento de su pase a tales situaciones.

${ }^{37}$ La base reguladora de las pensiones se calcula de forma parcialmente distinta si ya era pensionista de jubilación en el momento del fallecimiento, pues la base reguladora es la pensión ordinaria de jubilación o retiro que efectivamente se hubiera señalado al causante, debidamente actualizada en su caso. Si el pensionista de jubilación o retiro por IP para el servicio, no tuviera acreditados como mínimo 20 años de servicios efectivos al Estado, la base reguladora será la pensión de jubilación o retiro en la cuantía inicialmente reconocida del 75 por ciento. Por otra parte, si el causante fallece en situación de excedencia voluntaria, de suspensión firme, separado del servicio o en situación militar legalmente asimilable, es la pensión de jubilación que le hubiera correspondido al causante, pero considerando solamente por los servicios prestados hasta el momento de su pase a tales situaciones.

${ }^{38}$ Sobre las mismas, vid. SÁNCHEZ PERIS, V.: Los derechos pasivos de los funcionarios públicos: noción genérica de la Seguridad social. Recuperable en: http://www.valentinsanchezperis.com/LOSDERECHOS.pdf, pp. 37 y ss. 
49.2 TRLCPE). Ello, no obstante, se aplica el tope máximo de pensiones públicas, lo que ha recortado la ventaja comparativa que estas pensiones representaban respecto a las causadas por contingencias profesionales en el RGSS ${ }^{39}$. Ahora bien, en el caso de pensiones extraordinarias derivadas de actos de terrorismo no están sujetas a los límites de la pensión máxima de la LPGE.

\subsection{Crisis económica y presupuestos al margen de la Seguridad Social.}

Los RESSFP están incluidos en los presupuestos generales del estado y no en los propios de la Seguridad Social. Tanto las Mutualidades de funcionarios públicos como el RCP tienen un patrimonio y tesorería propios, por lo que sus fondos no integran el presupuesto de la Seguridad Social ni forman parte de la caja única del sistema. Con el traspaso de gestión establecido en el RD-L 15/2020, se prevé que el Estado realizará la correspondiente aportación económica (DA 7a). Además, el RCP tiene normas específicas de cotización. Las especialidades en el régimen de cotización se plasman en dos elementos. En primer lugar, los tipos de cotización de los funcionarios integrados en los RESSFP son diferentes de los de los trabajadores y funcionarios integrados en el RGSS. Así el empleador (el Estado) aporta el 18,3\% frente al 23,6\% del empresario del RGSS, y el funcionario del RCP aporta el 3,86\% en lugar del 4,7\% de los asalariados y funcionarios integrados en el RGSS.

En segundo lugar, esos tipos de cotización se aplican a los llamados haberes reguladores y no a los salarios reales. Los haberes reguladores son bases tarifadas en las que se clasifican los funcionarios a efectos de derechos pasivos para cada año en los $\mathrm{PGE}^{40}$, siendo iguales las de todos los funcionarios pertenecientes a un mismo grupo con independencia de sus retribuciones reales. Los diferentes tipos de cotización y su aplicación a los haberes reguladores y no a los salarios reales, arrojan en general, una cotización más baja que los funcionarios incluidos en el RGSS. En efecto, a diferencia de lo que ocurre en otros regímenes del sistema de seguridad social, las bases de cotización están objetivadas y no son los salarios reales percibidos por el funcionario (como, por ejemplo, ocurre para los funcionarios incluidos en el RGSS). Esta objetivación provoca que exista una muy alta tasa de reposición entre el sueldo en activo de los funcionarios en RCP y su pensión de jubilación, pues su haber regulador coincide con la última base de cotización, dando lugar a que sea el Régimen con la tasa de sustitución más elevada.

Los regímenes se nutren además de las aportaciones estatales. Respecto a éstas en el RCP el Estado no contribuye con una cuota fija, sino que la diferencia estatal viene dada por la diferencia entre lo recaudado por las cuotas de derechos pasivos de los funcionarios y el importe de las obligaciones a su cargo por pensiones, lo que ha permitido compensar el déficit creciente de este régimen derivado entre otros factores de que desde el 2011 no entran nuevos funcionarios en el RCP, sino en el RGSS, y estos cotizan como todos.

\subsection{Las peculiaridades en la jubilación}

En punto a la jubilación de los funcionarios, hay una cierta ambivalencia. Existen aspectos donde el legislador ha optado por equipararlos con los trabajadores y otros donde se mantienen diferencias sustanciales. En cuanto a lo primero, el período mínimo de cotización está igualado con

\footnotetext{
${ }^{39}$ LÓPEZ LORENZO, A., La protección social de los Funcionarios públicos, Editorial de la Universidad de Granada, Granada, 2007, p. 795

${ }^{40}$ La clasificación sería la clásica de: A1, titulados superiores; A2, titulados medios, C1 administrativos; C2 auxiliares administrativos y E, resto.
} 
el exigido en el RGSS. Sin embargo, hay un matiz importante, en los casos de jubilación por incapacidad permanente existe una particularidad en los funcionarios integrados en el RCP. A estos se le computan como años de servicio cotizados no sólo los efectuados, sino los que el funcionario hubiera podido cumplir hasta llegar a la edad de jubilación. Se trata de un claro privilegio. En cambio, se ha producido una equiparación en la llamada jubilación flexible (introducida por el RD-L 5/2013).

Sin embargo, se mantienen otras especialidades notables en tres tipos de jubilaciones: la forzosa, la voluntaria y la derivada de incapacidad permanente.

\subsubsection{La jubilación forzosa}

La primera peculiaridad es que en el ámbito funcionarial la jubilación forzosa rige plenamente, a diferencia de para los trabajadores donde es voluntaria. Generalmente, la jubilación forzosa se produce a los 65 años, aunque hay algunos colectivos que se jubilan forzosamente más tarde (profesores de universidad a los $70^{41}$ o a la finalización del curso académico en que los cumplan, magistrados, jueces, fiscales y secretarios, a los $70^{42}$ ) y otros colectivos como los militarles que pueden pasar antes del retiro por jubilación a la situación de reserva. En todo caso, el que la edad de jubilación forzosa se sitúe en los 65 años como regla general no deja de ser llamativo, por el retraso progresivo de la edad de jubilación de los trabajadores (Ley 27/2011) y de los funcionarios integrados en el RGSS. ¿Por qué esta diferencia? Exceptuando los casos anteriores, es llamativo también que la edad de jubilación para los funcionarios públicos, incluidos los integrados en el RGSS ${ }^{43}$, sea en general, de 65 años en contraste con el retraso progresivo de la edad de jubilación de los trabajadores. Esta diferencia se interpretaría no tanto por una búsqueda de un rejuvenecimiento de plantillas por el progresivo envejecimiento del colectivo funcionarial, sino como una vía de amortización del empleo público facilitando su jubilación.

Existe un segundo tema polémico al hilo de la jubilación de los funcionarios. Aunque la jubilación forzosa por edad sea la regla en los funcionarios públicos, en determinados casos se puede prolongar la situación de activo hasta los setenta años. Coexisten diferentes supuestos de prolongación que serían esencialmente dos: por falta de las cotizaciones necesarias en el momento de alcanzar la jubilación y por la solicitud de prórroga en el servicio activo.

Esta última posibilidad ha generado cierta conflictividad política y jurídica en los últimos años, en particular, en relación con algunos funcionarios de sanidad, al serles denegada esta prolongación ${ }^{44}$. Esto puede ser llamativo, pero lo cierto es que las protestas funcionariales se han producido generalmente con mayor intensidad cuando se les ha adelantado la edad de jubilación que tenían prevista. En 1984 se rebajó la edad de jubilación de los funcionarios a los 65 años y esta rebaja no fue interpretada como un avance social, en particular en los niveles más altos de la Administración, sino como una merma de ingresos que se producía al cesar en su vida activa por las diferencias entre el salario en activo y los haberes pasivos. No es intrascendente poner de manifiesto que diversas sentencias del Tribunal Constitucional han reconocido que no existe un derecho adquirido de los funcionarios a

\footnotetext{
${ }^{41}$ Pudiendo optar por jubilarse a la finalización del curso académico en que hubieran cumplido dicha edad (regulada en la Ley 27/1994)

${ }^{42}$ Magistrados, Jueces, Fiscales y Secretarios Judiciales se jubilan forzosamente a los 70 años, si bien pueden jubilarse a partir de los 65 años (arts. 386 y 445 LOPJ). En algunos cargos no está previsto una edad de jubilación forzosa, es el caso de los magistrados del Tribunal Constitucional o los Consejeros Permanentes del Estado.

${ }^{43}$ Para éstos también se fija la jubilación a la edad ordinaria de sesenta y cinco años, sin coeficiente reductor, en el art. 11 del RD-L 20/2012.

${ }^{44}$ Sobre el caso polémico de los médicos de la sanidad madrileña durante los años 2012 y 20013, vid. http://sociedad.elpais.com/ sociedad/2013/05/02/actualidad/1367523764_491859.html.
} 
jubilarse a una edad de jubilación determinada (la del momento de su ingreso a la función pública), sino que el régimen funcionarial puede ser alterado por la potestad del legislador, pudiendo causar en algunos casos unos perjuicios compensables económicamente ${ }^{45}$. El Tribunal Supremo, no sin ciertas vacilaciones, acabaría por rechazar la posible responsabilidad patrimonial del Estado por la anticipación de la edad legal de jubilación respecto a la regulación anteriormente prevista en esencia, al no tratarse de un derecho patrimonializado del funcionario ni una medida expropiatoria de derechos ${ }^{46}$.

En la actualidad, el tema ha vuelto a ser polémico desde otra perspectiva. Esta posibilidad se condiciona en el art. 67.3 EBEP a que se pida, debiendo resolver de forma motivada la Administración. Alguna sentencia del Tribunal Supremo del 2012, ya ha rechazado la denegación por la Administración de la solicitud de permanencia en el servicio si no estaba suficientemente motivada y se justificaba por alegaciones genéricas. ¿Por qué se habrían producido el conflicto? La Administración alegaría que algunos colectivos prolongaban automáticamente su jubilación, y no siempre era necesario, así como la necesidad de un rejuvenecimiento de plantillas (por ejemplo, nuevos médicos jóvenes) en un colectivo envejecido (se calcula que la medida de edad de los funcionarios está en los 50 años). Los afectados respondieron que con ello no se había buscado un rejuvenecimiento de la plantilla para mejorar el servicio, sino ahorrar, luchar contra el déficit y amortizar empleo público facilitando su jubilación. Lo cierto es que el paso a la jubilación en el caso de los altos empleados puede provocar una merma de sus ingresos por las diferencias entre el salario activo y los haberes pasivos, de ahí las peticiones de prolongación de la vida activa, en particular en los niveles altos de funcionarios de la Administración.

Con carácter particular ha de hacerse mención del personal militar, que previamente a la situación de retiro conforme al RCP, pasa a la llamada situación de "reserva", a la que accede en función del empleo y la categoría conforme a un sistema complejo, y donde pueden ocupar eventualmente destinos, y donde la retribución se produce no según la legislación de clases pasivas, sino de acuerdo con el sistema retributivo del personal de las Fuerzas Armadas.

\subsubsection{La jubilación voluntaria}

Junto a la jubilación forzosa se mantiene una vía diferente, la de la jubilación voluntaria, que exige como regla general, que el interesado tenga cumplidos sesenta ańos de edad y reconocidos treinta ańos de servicios efectivos al Estado (art. 28.2.b) TRLCPE), o bien que exista una disposición legal específica que lo permita con carácter general o para un colectivo de funcionarios. Un buen ejemplo, por ser el supuesto más utilizado es la llamada jubilación LOGSE (Ley 2/2006), para los funcionarios docentes. En cuanto a otras disposiciones legales que permiten una jubilación anticipada voluntaria, cabe mencionar diversas situaciones: el Personal de las Cortes Generales, podrá jubilarse voluntariamente cuando cumpla 60 años de edad o tenga reconocidos 35 años de servicios efectivos a las Cortes Generales o a cualquier otro ente público ${ }^{47}$. Asimismo, los funcionarios de los Cuerpos Docentes Universitarios podrán jubilarse voluntariamente al cumplir 65 años $^{48}$. Los Magistrados, Jueces, Fiscales y Secretarios Judiciales también al cumplir dicha edad, pero si lo solicitan con 6 meses de antelación de su órgano de jubilación (arts. 386 y 445 LOPJ).

El régimen de jubilación voluntaria previsto con carácter general para los funcionarios de clases pasivas mejora el RGSS, pues puede no existir una minoración del importe de la pensión

\footnotetext{
${ }^{45}$ Entre muchas otras, STC 70/1988, de 19 de abril.

${ }^{46}$ SSTS, Sala C-A de 30-11-92 y de 18-1-00, Rec. 692/94.

${ }^{47}$ Art. 17.3 Acuerdo de 27-3-06.

${ }^{48}$ Ley 27/1994.
} 
anticipada $^{49}$ (cfr. art. 161.bis LGSS, que sí se aplica a los funcionarios integrados en el RGSS) y contrasta con la opción de política de derecho de dificultar las jubilaciones anticipadas. Así, se ha excluido a los funcionarios del RCP de la aplicación del régimen previsto para los trabajadores y los funcionarios integrados en el RGSS en el art. 215 TRLGSS y en la DT 4a TRLGSS. En efecto, los funcionarios sujetos al RGSS pueden acogerse a la jubilación anticipada prevista en la TRLGSS, si bien, en estos casos se establece una reducción de la prestación que recibirá el jubilado anticipado en función de los años que le falten para aquella edad. Además, los funcionarios del RGSS podrán acogerse a otras jubilaciones anticipadas que puedan estar previstas eventualmente en la regulación administrativa de su relación de servicios.

Como quiera que la regulación del RCP ha sido más beneficiosa que la del RGSS, se producían traspasos de solicitudes de jubilación anticipada en este Régimen, de modo que se introdujo alguna limitación. En concreto, en punto al requisito de treinta años, a partir del 1-1-2011, se exige que los últimos cinco años de servicios estén cubiertos en el RCP, cuando para completar los treinta ańos de servicios exigidos hubieran de computarse períodos de cotización a otros regímenes, por aplicación de las normas sobre cómputo recíproco de cuotas entre regímenes de Seguridad Social (las especificidades se regulan en la DA 16a TRLCPE).

Por último, es importante resaltar que no es posible la jubilación parcial para los funcionarios. Ello supone un detrimento respecto al colectivo de trabajadores por cuenta ajena. Sin embargo, en cuanto a la jubilación anticipada, se ha excluido a los funcionarios del RCP de la aplicación del régimen previsto para los trabajadores y los funcionarios integrados en el RGSS en el art. 215 TRLGSS y en la DT 4a TRLGSS. En efecto, los funcionarios sujetos al RGSS pueden acogerse a la jubilación anticipada prevista en la TRLGSS, si bien, en estos casos se establece una reducción de la prestación que recibirá el jubilado anticipado en función de los años que le falten para aquella edad. Además, los funcionarios del RGSS podrán acogerse a otras jubilaciones anticipadas que puedan estar previstas eventualmente en la regulación administrativa de su relación de servicios.

\subsubsection{La jubilación por incapacidad permanente}

En el RCP la IP se configura como una causa de jubilación, y no como una prestación autónoma. Además, como singularidad, no existe una distinción por grados, de IP total, absoluta, y gran invalidez. Sin embargo, lo cierto es que, por el impacto de alguna sentencia del Tribunal Constitucional, como la 134/96, de 22 de julio, dictada sobre el trato fiscal de las pensiones por IP en el RCP respecto a las pensiones de IP del sistema de Seguridad Social, ha motivado que generalmente en la resolución de jubilación por IP del funcionario se haga constar el grado a efectos de la exención del IRPF para las pensiones de IP absoluta o gran invalidez. Además, también ha de matizarse que a través de las mutualidades de funcionarios se puede obtener un complemento de la pensión diferente según el grado de IP.

Por otra parte, en el caso de la jubilación por IP se ha establecido una regla específica para situaciones equivalentes a una IP total, esto es cuando la inutilidad impida continuar desempeńando el puesto de funcionario, pero no inhabilite para toda profesión u oficio y acredite menos de 20 años de servicios efectivos ${ }^{50}$. En este caso, se producirá una minoración de un $5 \%$ sobre la cuantía íntegra (aunque exceda del importe de la pensión máxima) por cada año que falte para cumplir los 20 años de servicios efectivos. El máximo es una reducción del 25\% para quienes acrediten 15 años o menos

\footnotetext{
${ }^{49}$ El coeficiente reductor se aplica por cada ańo de servicio anterior a los 35, de manera que si un funcionario cuenta con 35 años de servicio no sufre minoración en su pensión.

${ }^{50}$ DA $13^{a}$ de la Ley 2/2008, desarrollada por el RD 710/2009, de 17 de abril.
} 
de servicios efectivos ${ }^{51}$. Esta reducción en la cuantía puede eliminarse si con anterioridad se produce una agravación que impida desempeñar toda profesión u oficio, percibiendo en ese caso el 100 por 100 de lo que le hubiera correspondido ${ }^{52}$. Tampoco se aplica esta reducción a las pensiones extraordinarias. Además, a efectos de las prestaciones por muerte y supervivencia que pudiera causar el beneficiario de esas pensiones reducidas respecto a sus familiares, la base reguladora del causante ascenderá a la pensión íntegra de jubilación o retiro, sin reducción, salvo que el funcionario fallecido hubiera realizado una actividad con posterioridad a su jubilación o retiro encuadrada en algún régimen de la seguridad social, en cuyo caso la base reguladora será del 75\% del importe de la pensión reconocida.

Para determinados funcionarios del cuerpo nacional de policía, personal de las fuerzas armadas y guardia civil, pueden existir situaciones donde no obstante producirse una disminución de las funciones propias de su puesto de trabajo, no se acuerda necesariamente la jubilación o retiro por IP para el servicio, si no situaciones de "segunda actividad" 53 o limitaciones para ocupar determinados destinos o el cambio de especialidad.

Además, el RD 1186/2001, de 2 de noviembre, establece una regulación particular de la protección del RCP para determinados militares cuando se produzca un accidente, lesión o enfermedad determinantes de la insuficiencia de condiciones psicofísicas ${ }^{54}$.

\section{Conclusiones}

En el Real Decreto 15/2020, de 21 de abril, de medidas urgentes complementarias para apoyar la economía y el empleo, se contiene una disposición que, en teoría, no reviste ninguna conexión con los paquetes de medidas laborales y fiscales aprobados para paliar los efectos de la crisis económica derivada de la pandemia. Se trata del traspaso de competencia de la gestión de las pensiones de los funcionarios integrados en el RCP al Ministerio de Seguridad Social. El cambio de gestión del régimen de clases pasivas al INSS es lógico y contribuye a la integración del sistema, aunque sólo constituye una pequeña transformación por dos razones. En primer lugar, el cambio de gestión de una de las cuatro patas de los Regímenes Especiales de Funcionarios como es el RCP, mantiene la estructura de estos regímenes y sus singularidades. En segundo lugar, el cambio en la gestión del Ministerio de Hacienda hacia la Dirección General de Ordenación de Seguridad Social, no ha afectado directamente a los pensionistas. Es cierto que se han producido una reforma en la normativa que regula las clases pasivas, pero los cambios de articulado, aunque numerosos son, en síntesis, reformas técnicas dirigidas a aclarar el órgano gestor de las prestaciones. Pese a la alarma creada en algunos medios de comunicación entre los pensionistas, no se han modificado ninguna de las prestaciones del RCP, ni se han alterado sus requisitos, ni cuantías. Tampoco respecto a los futuros pensionistas se han

${ }^{51}$ El cómputo de los años de servicio incluye también los períodos de cotización en otros regímenes de Seguridad Social, siempre que se haya procedido a la aplicación de las reglas de cómputo recíproco (art. 1.2 RD 710/2009).

${ }^{52}$ No obstante, este incremento de cuantía es incompatible con una pensión que se pudiera reconocer computando los períodos de ejercicio de una actividad por cuenta propia o ajena que motive la inclusión en un régimen público de Seguridad social.

${ }^{53}$ Se trata de una situación para funcionarios del cuerpo nacional de policía donde el funcionario es apartado del servicio activo, percibiendo unas retribuciones especiales, si bien puede acceder a determinados puestos de gestión, asesoramiento o similares, percibiendo en ese caso, las retribuciones correspondientes al ejercicio de esas funciones como si estuviera en activo.

${ }^{54}$ En concreto, se aplica a los militares de complemento y los militares profesionales de tropa y marinería con una relación de servicios profesionales no permanente, así como para determinados alumnos de formación militar, de cuerpos a extinguir como el personal de escalas de complementos y reserva naval y ciertos reservistas que pasen a la situación de activo. Para ello habrá de tramitarse el pertinente expediente de valoración de las condiciones psicofísicas dentro de la Sanidad Militar, pero la determinación del grado de minusvalía no tomará en cuenta las normas específicas del ámbito militar, sino el baremo previsto en una norma general como es el RD 1971/1999. 
producido cambios en las modalidades o coberturas de las pensiones del sistema. Ni tampoco en las distintas mutualidades de funcionarios, que tienen una gestión y una regulación separada del RCP.

De manera que se mantiene como régimen a extinguir, traspasándose únicamente su gestión al INSS. Si ello es así, ¿̨por qué algunos sindicatos en la función pública han mostrado preocupación por estos cambios meramente técnicos y se han mostrado preocupados? Pues sencillamente porque el hecho de que, siendo el mismo organismo gestor, transitoriamente la Dirección General de Ordenación de Seguridad Social, y posteriormente el INSS, es probable que el cambio abra una vía para cuestionar la autonomía y separación de los RESSFP, debatiéndose si determinadas conquistas o, si se quiere utilizar una connotación negativa, privilegios sean más evidentes y, con ello más difíciles de justificar.

El origen del cambio de gestión en el RCP no parece responder a una agenda oculta. De hecho, el arranque se situaría en el art. 22 del Real Decreto 2/2020, de 12 de enero, por el que se reestructuraron en dicho ańo los departamentos ministeriales aludiendo a las clases pasivas como competencia del Ministerio de Seguridad Social. Ello, no se contenía en otros reales decretos anteriores de reorganización de los departamentos ministeriales, que se suelen aprobar al principio de cada legislatura. En todo caso, parece claro que el gobierno pretendía llevar la gestión de Clases Pasivas al Ministerio encargado de la gestión de Seguridad Social ya antes de la declaración del estado de alarma.

En la exposición de motivos del Real Decreto-ley 15/2020 se justifica la urgencia y necesidad del cambio de gestión del RCP señalando esencialmente que como la tramitación parlamentaria de los cambios normativos para operar el traspaso en la vía ordinaria retrasaría la organización del Ministerio de Seguridad Social, se generaría incertidumbre en la gestión de la delicada cuestión de las pensiones. A primera vista, no parece que existiera una situación perentoria que implicase la necesidad de encajar en una norma dedicada a medidas económicas y de empleo por la crisis del COVID-19, un cambio en la gestión de la gestión de pensiones de Clases Pasivas, que no guardan ninguna relación con otras medidas vinculadas a la crisis sanitaria. Pero ello no implica necesariamente que la vía empleada sea ilegal por la flexible interpretación del tribunal constitucional sobre el uso de esta norma.

Justamente, en este último sentido, el uso del Decreto-ley para aprobar una reforma como la operada en la gestión del RCP, plantea la cuestión de si está justificada su utilización tanto por la materia que es objeto de Decreto-ley, como por el requisito de la urgencia y extraordinaria necesidad en su aprobación. El Real Decreto Ley se ha apoyado en una motivación típica de este tipo de norma. Así, se hace hincapié en que el Decreto-ley, por su mayor rapidez, evitaría distorsiones al producirse la reestructuración del ministerio de Seguridad social con mayor rapidez. Si se lleva a sus últimos términos, esta misma argumentación serviría para toda reforma en materia de pensiones, que siempre podría crear distorsiones, al ser siempre un tema sensible.

Entonces si no existía una extraordinaria y urgente necesidad, ¿por qué razón el gobierno ha decidido acometer este cambio mediante una legislación de urgencia? Creo que sinceramente responde a que el estado de alarma ha ofrecido la oportunidad de iniciar un cambio en la siempre delicada cuestión de las pensiones de funcionarios públicos aprovechando la multitud de legislación de urgencia aprobada durante la pandemia. La aprobación de reformas laborales y de Seguridad Social mediante esta forma legislativa se había convertido, en algo más que en una vía excepcional, ya antes de la crisis sanitaria, económica y social, acentuándose con ésta.

\section{Bibliografía}

ALARCÓN CARACUEL, M.C.: “Reflexión crítica sobre la reforma laboral de 2001", Revista de Derecho Social, núm. 15, 2001, pp. 35-72. 
ALARCÓN CARACUEL, M.R. y GONZÁLEZ ORTEGA, S.: Las pensiones de los funcionarios públicos en España, Fundación Mapfre, Madrid, 1988.

ALFONSO MELLADO, C.L., "La jubilación anticipada y la prejubilación de los funcionarios públicos”, en AA.VV. (coord. LÓPEZ CUMBRE), Tratado de jubilación, Iustel, Madrid, 2007.

BLASCO LAHOZ, J.F.: La gestión de la Seguridad Social: entidades gestoras, servicios comunes, mutuas colaboradoras con la seguridad social, empresas colaboradoras con la seguridad social y mutualidades de funcionarios públicos, Tirant lo Blanch, Valencia, 2016.

BLASCO LAHOZ, J.F., LÓPEZ GANDIA, J. y MOMPARLER CARRASCO, M.A.: Regimenes Especiales de Seguridad Social de los Funcionarios, Tirant lo Blanch, Valencia, 2011.

CALVO RAMÍREZ, C.: "Régimen de Clases Pasivas de los funcionarios del Estado", Revista de Seguridad Social, núm. 37, 1988.

CIRIANO VELA, C. D.: Principio de legalidad e intervención económica, Atelier, Barcelona, 2000.

DOLZ LAGO, M.J.: El régimen especial de seguridad social de los funcionarios de la Administración Civil del Estado, Tirant lo Blanch, Valencia, 2004.

ESCOBAR JIMÉNEZ, J.: La acción protectora de la Seguridad Social de los funcionarios públicos, Ibidem, Madrid, 1997.

GONZALO GONZÁLEZ, B.: Seguridad Social de los funcionarios públicos en España, Instituto de Estudios Fiscales, 1997, Madrid.

HERNÁNDEZ BEJARANO, M.: La protección sanitaria en los regímenes especiales de Seguridad Social de los funcionarios públicos, Bomarzo, Albacete, 2017.

HIERRO, L. L.: "El imperio de la ley y la crisis de la ley”, Doxa, 1996, núm. 19, pp. 287-308.

ITUREN OLIVER, A. y ESTEVE SEGARRA, A.: "El derecho de huelga en tiempos del estado de alarma por el COVID-19”. Trabajo y Derecho, núm. 65, 2020, pp. 1-21.

JORNADA DE POZAS, L.: “Tendencias modernas sobre el Régimen de Clases Pasivas”, en Estudios Sociales y de Previsión, Tomo II, Volumen 2, Ministerio de Trabajo, INP, Madrid, 1961.

LÓPEZ GARRIDO, D.: "Reflexiones sobre la constitucionalidad del Real Decreto Ley 1/1992, de medidas urgentes sobre fomento del empleo y protección por desempleo", Revista Española de Derecho Constitucional, núm. 38, 1993, pp. 13-48.

LÓPEZ LORENZO, A.: La protección social de los Funcionarios públicos, Editorial de la Universidad de Granada, Granada, 2007.

MONERO PÉREZ, J.L.: "Proceso de convergencia e integración de los regímenes de Seguridad Social: significación y aspectos útiles”, Temas Laborales, núm. 112, 2011, pp. 91-132.

MUÑOZ MACHADO, S.: "Las deformaciones del ordenamiento jurídico y la aplicación de las leyes en el nuevo sistema constitucional", en su obra Cinco estudios sobre el poder y la técnica de legislar, Civitas, Madrid, 1986, pp. 181 y ss.

PALOMEQUE LÓPEZ, M.C.: "La versión 2001 de la reforma laboral permanente", Revista de Derecho Social, núm. 15, 2001, pp. 9-34.

RODRÍGUEZ CARDO, I. La Seguridad Social de los empleados, cargos y servidores públicos, Aranzadi, Pamplona, 2008.

- La seguridad social de los militares en activo: el mutualismo militar, Ministerio de Trabajo e Inmigración, Subdirección General de Información Administrativa y Publicaciones, 2008, Madrid.

RODRÍGUEZ ESCANCIANO, S.: "Capítulo 9. Régimen especial de funcionarios civiles del estado", Tratado de Derecho de la Seguridad Social II, Laborum, Murcia, 2017.

RODRÍGUEZ RAMOS, M.J.: "Los derechos de Seguridad Social de los funcionarios públicos: convergencias y divergencias con el Régimen General”. Recuperable: https://idus.us.es/bitstream/handle/11441/44007/Los\%20derechos\%20de\%20seguridad\%20social 
SÁNCHEZ PERIS, V.: Los derechos pasivos de los funcionarios públicos: noción genérica de la Seguridad social. Recuperable en: http://www.valentinsanchezperis.com/LOSDERECHOS.pdf

SANTAMARÍA PASTOR, J.A.: "Principio de legalidad (Derecho Constitucional)", en la Enciclopedia Jurídica Básica, Vol. III, 1a ed., Civitas, Madrid, 1995, pp. 5078-5081.

SEMPERE NAVARRO, A.V.: "El lugar del Decreto-Ley en el cuadro de fuentes jurídico-laborales (Sentencia 29/1982, de 31 de mayo, pronunciada por el Pleno del Tribunal Constitucional en el recurso de inconstitucionalidad 238/1981", Revista de Política Social, núm. 135, pp. 239-251.

TORRES DÍEZ-MADROÑERO, P.: “La integración en el régimen general de la seguridad social de los funcionarios públicos a partir de 1 de enero de 2011: diferencias destacables con el régimen especial de clases pasivas del Estado", Revista del Ministerio de Empleo y Seguridad Social, núm. 104, 2013.

VIDA SORIA, J.: "Sobre la inactualidad del Régimen de Clases pasivas", Documentación Administrativa, núm. 71, 1963. 